\title{
نشأة النحو العربي
}

\section{Muhammad Afthon Ulin Nuha}

Institut Abdul Chalim Mojokerto

Email : jumbanji@gmail.com

الملخص: هذه المقالة تحت العنوان "نشأة النحو العربي". يركز بحث هذه المقالة في ( ) مفهوم

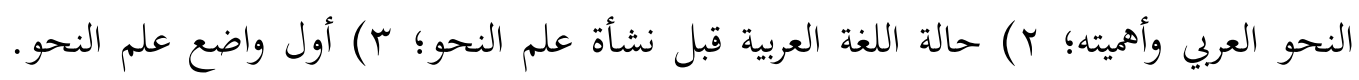

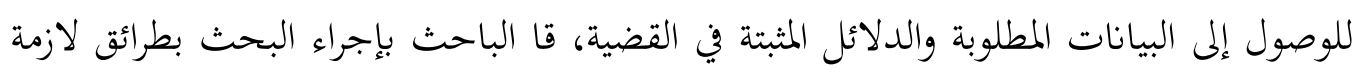

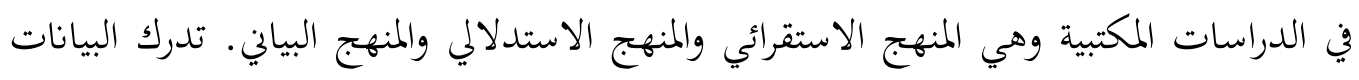

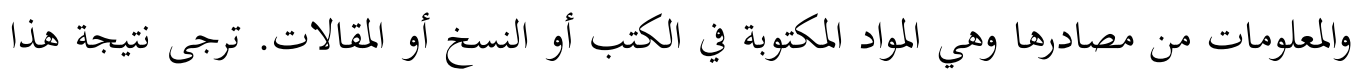

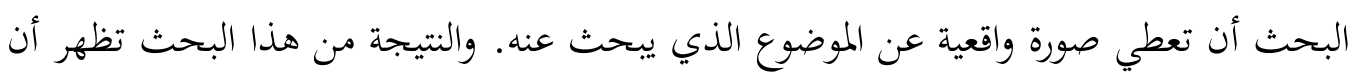

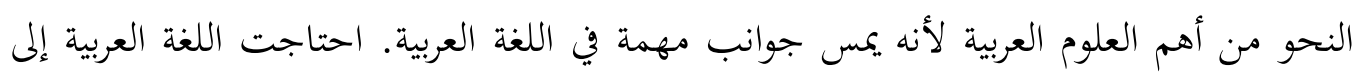
النحو لأن له وظائف مهمة في حفظ سلامتها من الفساد والاضطراب، بجانب إنه يساعد القراء

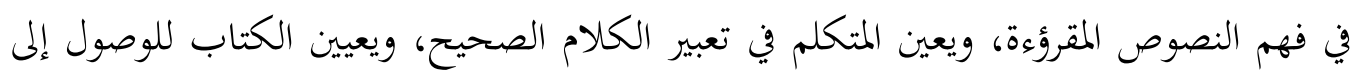
الكتابة الصحيحة، وقبل ظهور علم النحو كانت حالة اللغة العربية عاشت عيشة قوية، ولم تحتج إلى قواعد تحتفظ بها. وذلك لأن العرب يتكلمون بلغتهم قائمة على الفطرة السالمة والسليقة

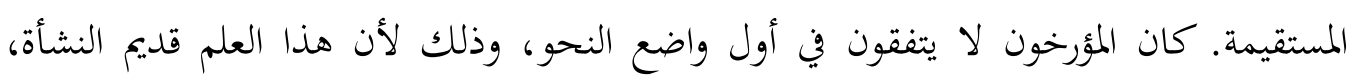

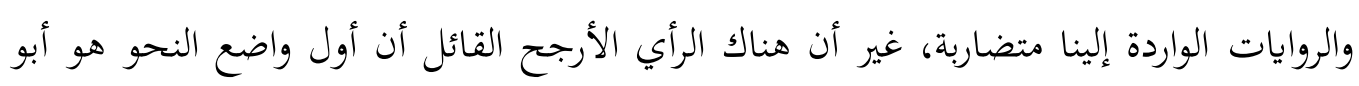
الأسواد الدؤلي تحت إرشاد الإمام علي رضي الله عنه.

الكلمات الرئيسية : النحو، اللغة العربية، الروايات

أ. أ. مقدمة

إن النحو يعتبر من أهم العلوم العربية لأنه يمس جوانب مهمة في اللغة العربية. إنه يحوى القواعد التي

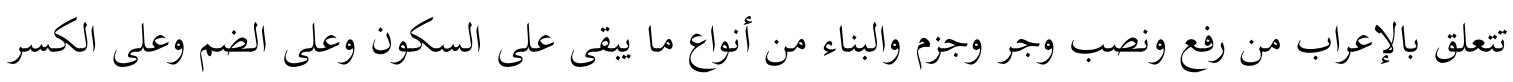

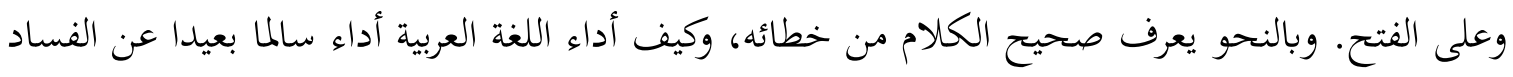

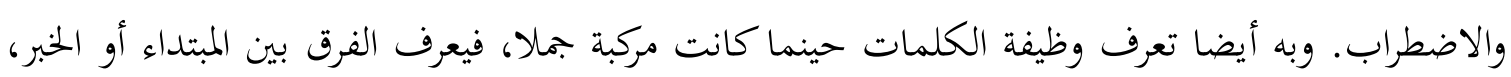


وبين الفاعل والمفعول، وبين الفعل المعلوم والمجهول، وبين الجملة الشرطية والإستفهامية، وبين التعجب والنفي وغير ذلك.

وبالجملة كان النحو يلعب دوراها ما في اللغة العربية، إنه ألة للوصول إلى تعبير الكلام الصحيح، وإنه ألة للوصول إلى القراءة الصحيحة وألة للوصول إلى الفهم المعنى المنصوص. وقد كتب العلماء قديما وحديثا البحوث النحوية في مائات كتاب على اختلاف طريقتها وأنماطها. وما زال طلاب المدارس والمعاهد الاسلامية في العالم الإسلامي منذ قديم إلى اليوم يدرسوها ويبحثون عنها تدريجيا من متنها إلى شرحها ومن صغيرها إلى متوسطها فإلى كبيرها. وإلى ذلك الحد اهتمام المسلمين والمدارس والمعاهد الإسلامية في دراسة النحو العربي، حتى قيل أن النحو أبو العلم والصرف أم العلم. ومع ذلك كان معظم دارسية قد يجهلون جانبا من جوانبه، وهو ما يتعلق بتاريخ نشأته. فيظهر منه تساؤلات ( ) ما هو علم النحو ؟؛ ؟) كيف حالة اللغة العربية قبل نشأة النحو ؟؟ r) من أول واضع النحو ؟. لإجابة هذه التساؤلات قام الكاتب بتقديم هذا البحث الوجيز فيما يلي.

\section{ب. مفهوم النحو لغة واصطلاحا}

النحو هو علم من علوم اللغة العربية المتعددة. وقد قسم مصطفى الغلاييني العلوم العربية إلى ثلاثة عشر علما وهي : الصرف والإعراب (يجمعهما اسم النحو) والرسم والمعاني والبيان والبديع والعروض والقوافي وقرض الشعر والإنشاء والخطابة وتاريخ الأدب ومتن اللغة. '

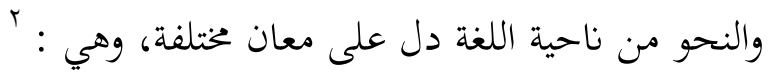
ا ـ المثل، نحو : خالد نحوك، أي مثلك

r الجهة، نهو : : توجهت نحو القبلة، أي جهة القبلة r. المقدار، نحو : عندي نهو ألف دينار، أي مقدار ألف دينار

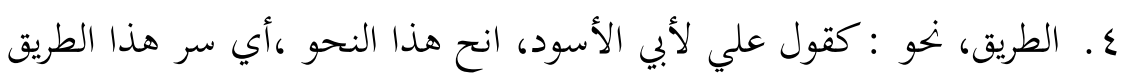

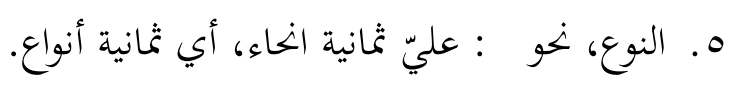
وقد جمعها بعضهم معنى النحو فن نظم :

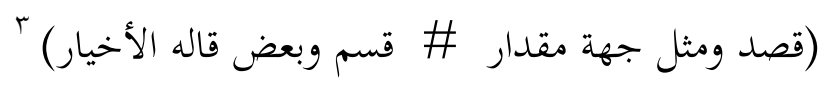
أما النحو من ناحية الاصطلاح فقد تعددت عبارات النحاة، منها : ا. قال الغلاييني: إنه علم بأصول تعرف بها أحوال الكلمات العربية من حيث الإعراب والبناء أي من حيث ما يعرض لها في حال تركيبها.

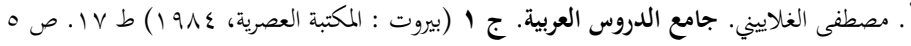

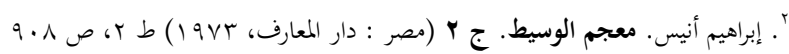

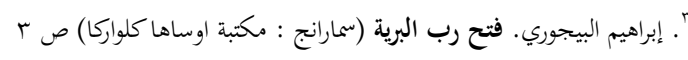

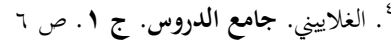


r. السيد أحمد الهاشىى رأى، النحو هو قواعد يعرف بها أحوال أواخر الكلمات العربية التي حصلت

$$
\text { بتركيب بعضها مع بعض من إعراب وبناء وما يتبعهما. }
$$

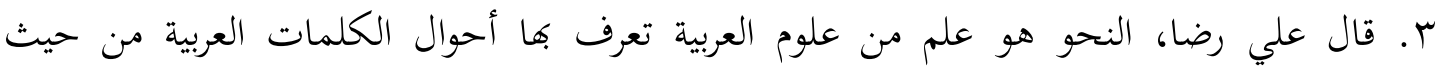

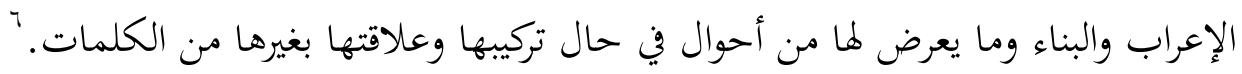

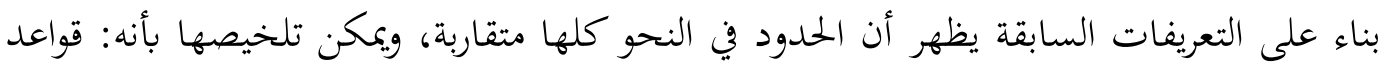

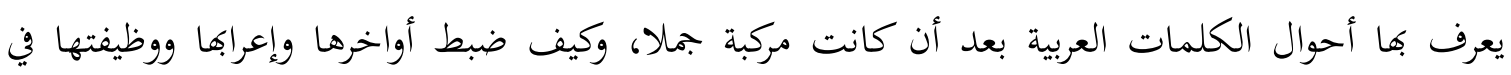

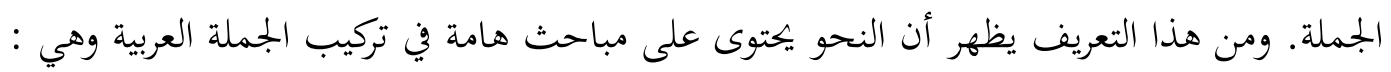
ا ا. المبحث عن أحوال الإعراب والبناء وما يتعلق بهما. r. المبحث عن أحوال الجملة العربية. r. المبحث عن وظيفة الكلمات داخل الجملة.

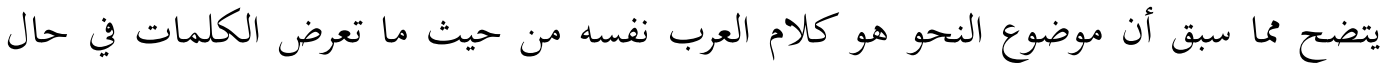

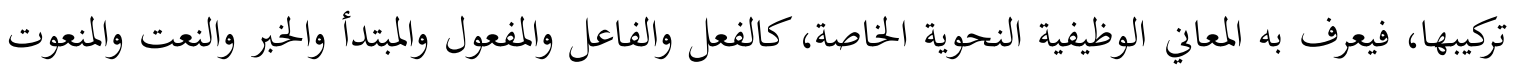

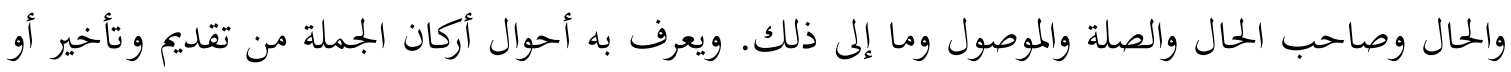
ذكر أو حذف أو إضمار أو إظهار وهلم جرا.

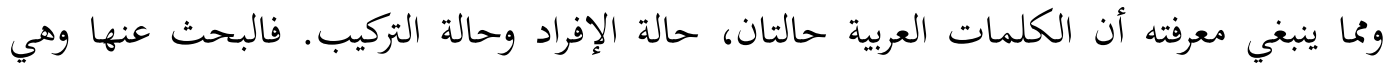

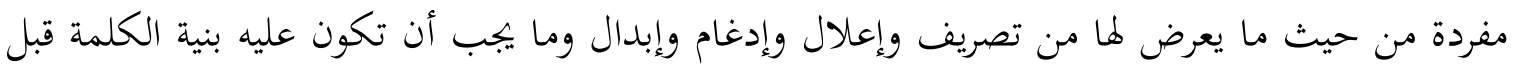

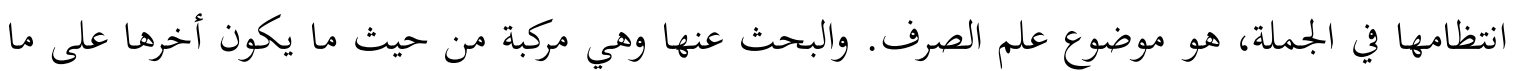

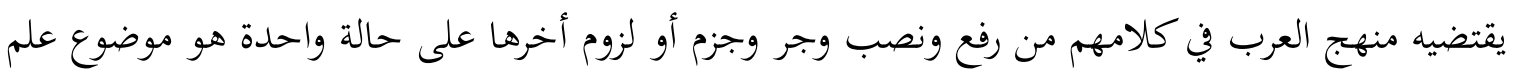
النحو.

النحو والصرف كلاهما بحث نهوي في النحو القديم. كما رأى ذلك مصطفى الغلاييني بقوله : وقد

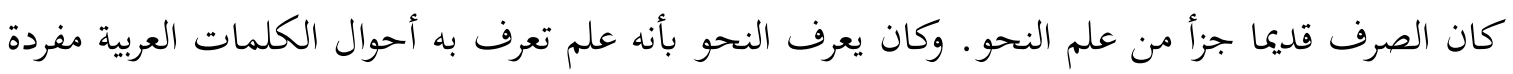

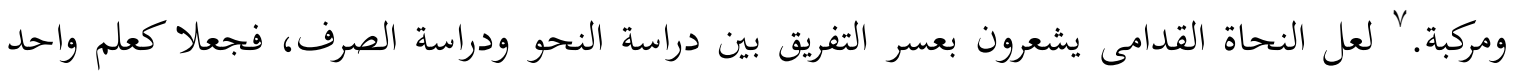

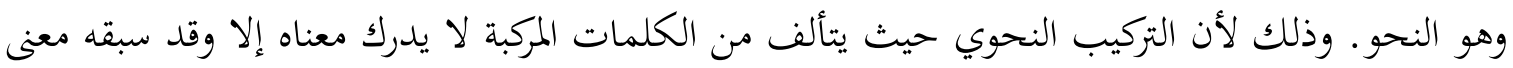

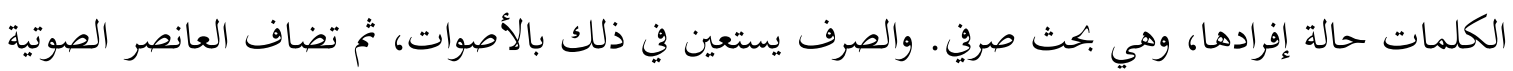

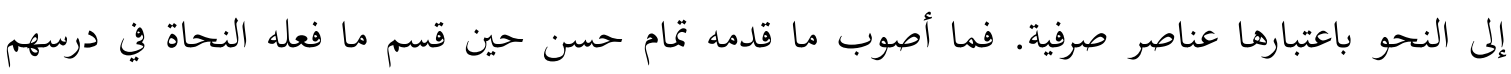

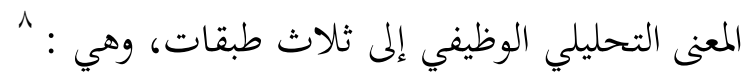


ا. دراسة الأصوات العربية، وقد فصل النحاة القول في وصف مخارجها وصفاتا فرادي، ثم تناولوا

$$
\text { بالدراسة ما رأوه منها داخلا في حين الإدغام كما فهموه. }
$$

r. دراسة الصرف التي كانوا فيها بالأصول والزوائد وبيان المشتق والجامد وتحديد اشكال الصيغ وحصر فيال فهوه

اللواحق وأماكن زياداتما، ثم ما يلحق الصيغ من إعلال أو إبدال أو حذف تهن.

r. دراسة النحو، قد حاولوا فيها تقسيم الكلام وبيان علامات كل قسم، تم كشفوا عن المعرب والمبني

من هذه الأقسام وشرعوا بعد ذلك في بيان الأبواب النحوية في داخل الجملة وما تمتاز به كل باب من علامات يعرف بها وبينوا بعض المعاني الوطيفية التي تؤديها العناصر اللغوية، كالتذكير والتأنيث والتعريف والتنكير والإفراد والتثنية والجمع والتكلم والحضور والغيبة وكالصرف وعدمه والعلامات

$$
\text { الإعرابية وهلم جرا. }
$$

ثم بعد أن تعينت موادها ومواضعهما في الدراسة، إخرج النحاة الصرف من مباحث علم النحو وجعلوه علما مستقلا منه، ولو كانت دراسة النحو لا تأمن دائما من اللبس بدراسة الصرف، لأن النحو يدرس الكلمات العربية بعد انتظامها في الجملة والصرف يدرسها قبل انتظامها فيها. والجملة لا يتصور وجودها إلا مؤلفة من المفردات التي هي مباحث الصرف. فأمر طبيعي إذا جاءت متون القواعد مشتملة على مزيج من هذا أو ذاك يصعب معه إعطاء ما للنحو للنحو وما للصرف للصرف. والصرف على وجه أخص يبحث عن صيغ الكلمات العربية من حيث دراسة الألفاظ لا ظهار ما في حروفها من إصالة أو زيادة أو حذف أو إبدال أو صحة أو إعلال أو قلب أو نقل أو إدغام أو تحويل

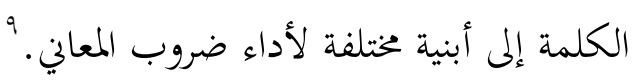

مما تقدم ذكره يظهر أن هناك فرقا بين مباحث النحو والصرف. فالصرف تكون مباحثه في الكلمات المفردة قبل انتظامها في الجملة. وذلك في الأسماء المتمكنة والأفعال المتصرفة، لا الحروف وما يبشه الحروف ولا الأفعال الجامدة. أما النحو فمباحثه الكلمات العربية بعد انتظامها في الجملة من تغيير أواخرها

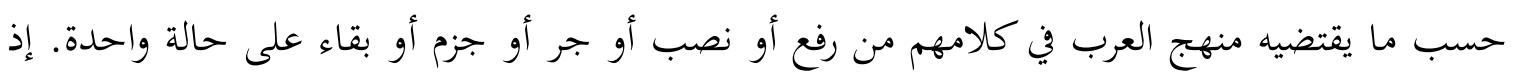
أن الصرف يتوقف بكثه حول تغيير أبنية الكلمات والنحو يتوقف بكثه حول تغيير أواخر الكلمات.

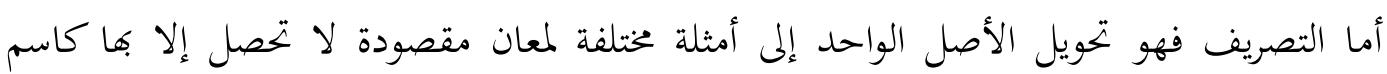
الفاعل والمفعول واسم التفضيل والتثنية والجمع وغير ذلك، ' والتصريف بغرضه المعنوي ينقسم إلى قسمين وهما الاصطلاحي واللغوي. 
عاشت اللغة العربية في العصر الجاهلي وعصر صدر الإسلام عيشة قوية مع أنه ليست لها قواعد وقوانين احتفظ بما العرب عن الخطاء في النطق والقراءة. وذلك لأن العرب يتكلمون بلغتهم قائمة على فلى الفطرة السليمة والسليقة المستقيمة، فلا يحتاجون إلى القواعد والقوانين. وإن قواعدهم للغتهم فطرة موروثة من

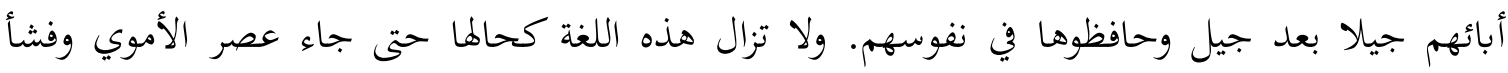

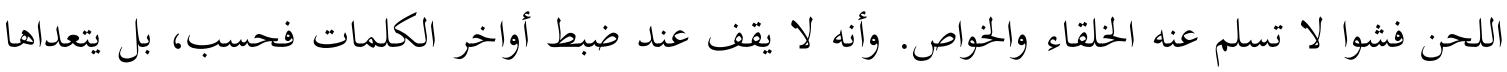

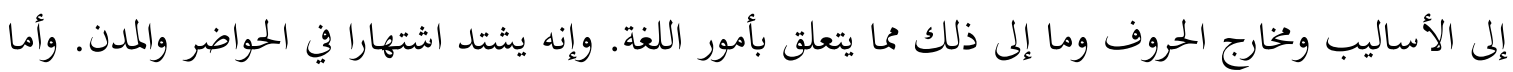

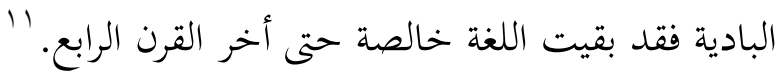
جرى هذا اللحن حتى يسوق العرب في حاجة ماسة إلى وضع القواعد والقوانين للغتهم تسلم بها

$$
\text { لغتهم من الانحراف والاضطراب. }
$$

والبحث في نشأة قواعد اللغة العربية يعتبر من أصعب البحوث فيه وذلك لأسباب منها : لأن هذا

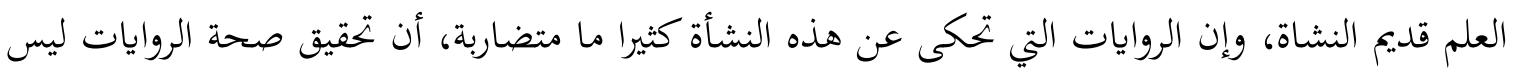
ميسورا، لعدم وجود الضوابط له مثل ما وجد في تحقيق الأحاديث النبوية.

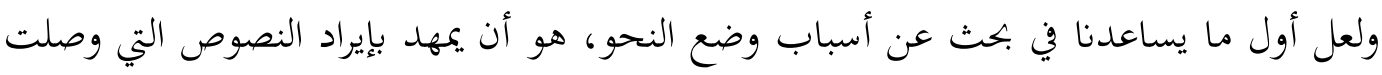

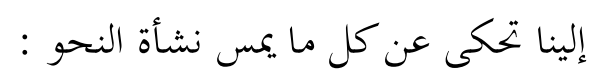
ا. روى بعض الرواة أن رسول الله (ص.م) سمع رجلا يلحن في كلامه فقال : أرشدوا أخاكم فإنه قد ضل. r. روى أن أحد ولاة عمر بن الخطاب (وهو أبو موسى الأشعري والي البصرة) كتب إليه كتابا ذكر

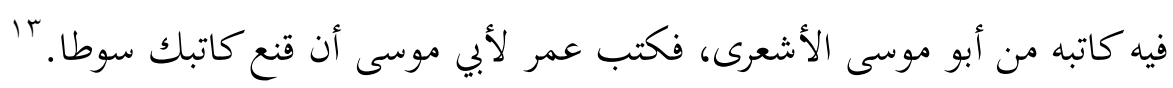

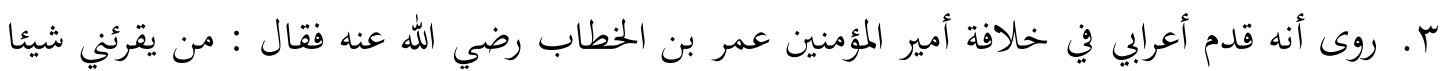

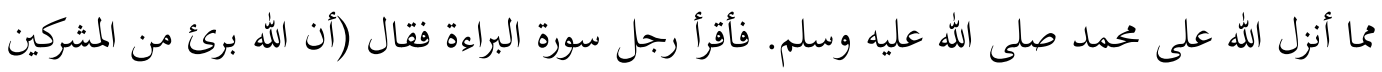

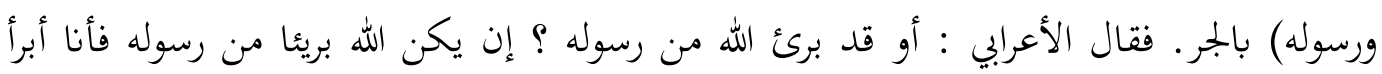

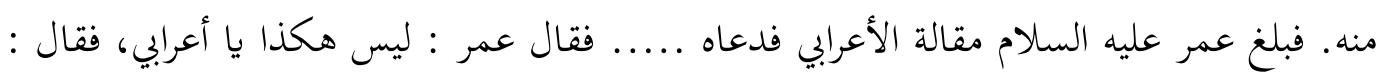

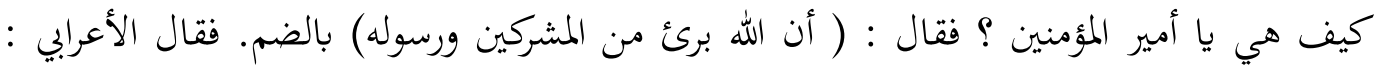

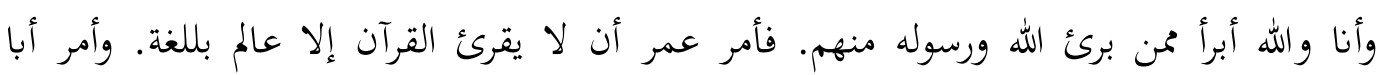
الأسود الدؤلي أن يضع النحو.

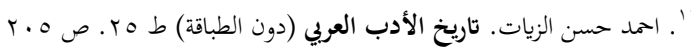

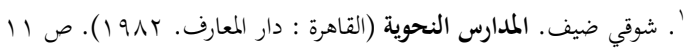

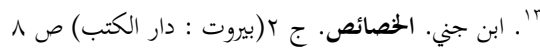

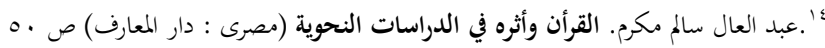


ع. روى عن ابن عمر. أنه قال : مرّ عمر على قوم قد رموارشقا فأخطأوا. فقال : ما اسوأرميكم، الحمال

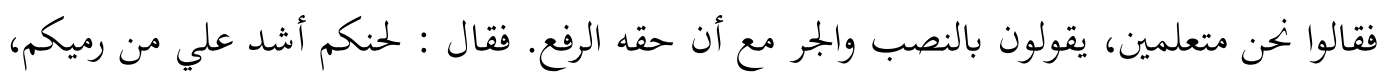
سمعت رسول الله (ص.م) يقول : رحم الله امرأ أصلح من لسانه. 10

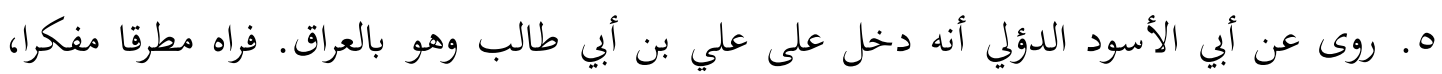

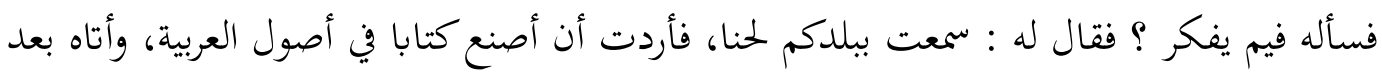

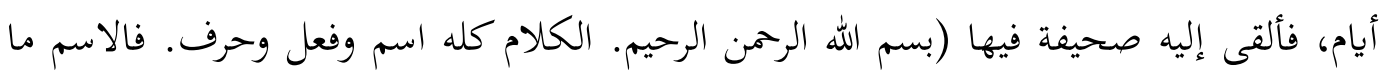

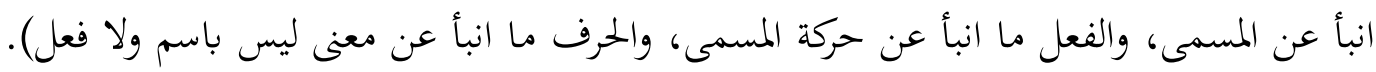

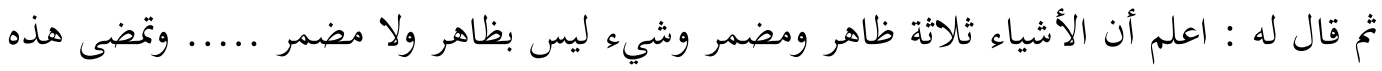

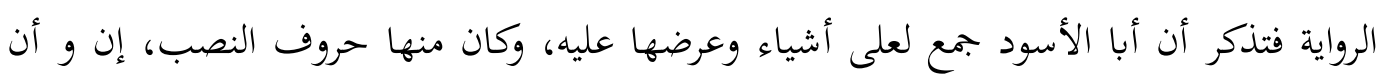

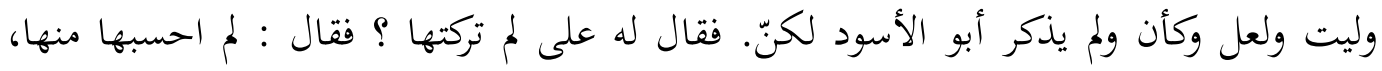
فقال : بل هي منها، فزدها فيها. 17

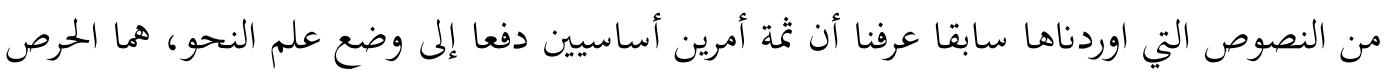
على سلامة القرأن من التحريف، وصيانة اللغة العربية من الاضطراب والفساد. ويبدو أن هذا الاهتمام باللغة

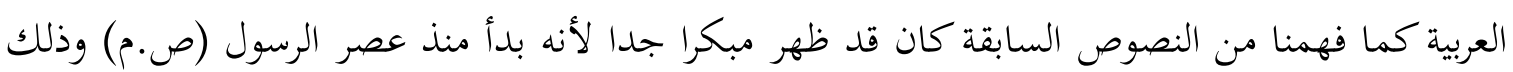

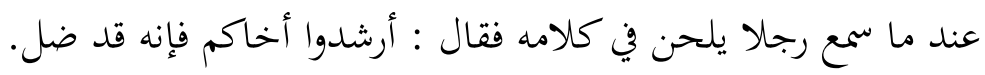

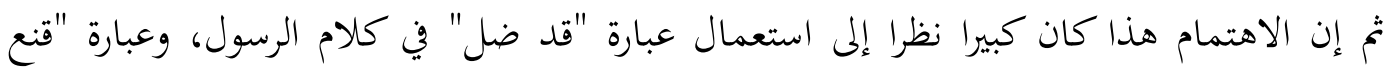

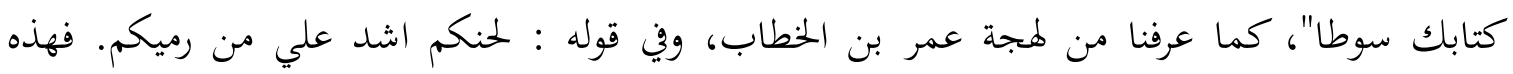

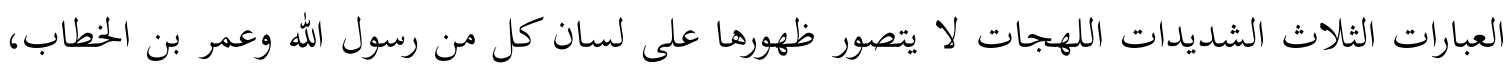
إلا إذا كان اللحن يعتبر أمرا عظيما.

واعتبار اللحن خطاء جسيما في نظرها لا يستدعي العجب لعلاقته بالقرأن، لأن القرآن الكريم نزل

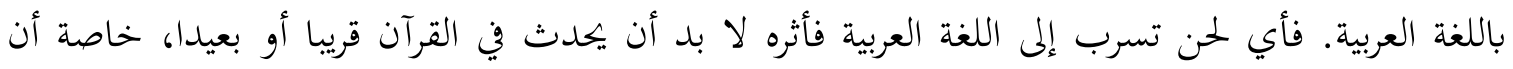
رقعة الدولة الإسلامية لم تعد محصورة في نطاق الجزيرة العربية، ومعتنقوا الإسلام لم يعودوا من الجنس العربي فقط، بل دخل فيه أجناس عدة لا عهد من قبل باللغة العربية.

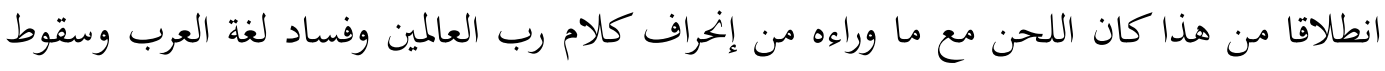

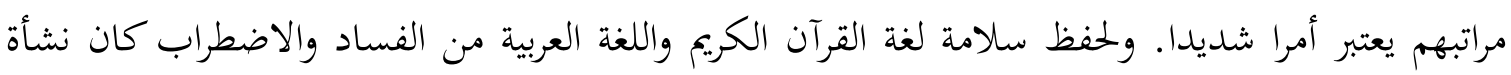
فن جديد حيث يموى القواعد العربية، تعتبر حاجة ماسة وعذرا شرعيا. 
ومن أهم الأسباب في نشأته وجود اللحن في قراءة آيات الذكر الحكيم. بدأ انتشار اللحن بعد الفتوحات الإسلامية في البلاد المجاورة بالبلاد العربية، مثل مصر والشام والعراق وفارس. فتلك الفتوحات تؤدى إلى أن يختلط مسلموا العرب بالأعلجم. فأخذ الأعاجم يتكلمون باللغة العربية في البلاد المفتوحة حيث يتكلم الأعاجم بها شيئا فشيئا حسب قدرتم حتى غلبت ما عداها. ومن ناحية أخرى فسدت فصاحة اللغة وظهر اللحن عند نطق تلك اللغة وعند قراءة القرآن الكريم. ومن البلاد المفتوحة، فالعراق أبرزها في اختراع العلوم وتدوينها. وكان اسبق الأقاليم مدينة وحضارة، تصنهاء حيث تعاقبت عليها الإمم المتحضرة من نحو ثلاثين قرنا قبل الميلاد. فالبابليون والأشوريون والكلدانيون والفرس واليونان، كل هؤلاء أنشأوا في العراق مما لك تختلف صبغتها، وكانت مدينتهم منارا يلقى اشعته على ما حوله من البلدان. ولما فتح المسلمون العراق ودان أهلها بالإسلام شعروا بالحاجة إلى تناول لغة دينهم العربية، ونشأ من ذلك افتقارهم إلى علم يوصلهم إلى تناول تلك اللغة. وعلى هذا فإن حاجتهم إلى النحو أشد من عرب البادية، لأكم يعرفون لغتهم ويتكلمون بها صحيحة على سليقتهم. فإذا كان الباعث على ظهور النحو مثل ما ذكر سابقا، كان طبيعيا أن يكون منشأة بلدا أعجميا، ولا أفضل في ذلك من العراق. هكذا كان الإسلام والفتح سببا في انتشار اللغة العربية مهما قد أتت بها أشياء لها خطرها، ومنها اختلاط العرب بالأعاجم كما مرّ ذكره. ونتيجة من هذا الاختلاط أخذ الفساد يدبّ في التكلم بين العرب والعجم وظهر اللحن فيه. فوعى المسلمون وبادروا إلى اتخاذ الوسائل لحفظ لغتهم العربية ودرء خطرها. فظهر في أرض العراق اهتمام عظيم في وضع علم النحو حيث يمفظ به سلامة اللغة العربية من الفساد والاضطراب. وإن منشأ هذا العلم الشريف في مدينة البصرة التي تعد من أهم المدن في العراق. كانت البصرة تقع على ممر عدة طرق تحارية مهمة، ولذلك اصبحت مركزا لحياة اقتصادية نشيطة واسعة، وأغلب سكاها من القبائل العربية التي كانت تقيم في شرقي الجزيرة العربية وبخاصة منطقة الخليج الفارسي. لم تكن البصرة في عزلة من الأعاجم والموالي الذين بدأوا يكتسحون الحواضر الإسلامية بسبب الفتوح، فقد جاء عبيد الله بن زياد بألفين من الإتراك الذين أسرهم في حملاته في أوأسط أسيا، فاسكنهم

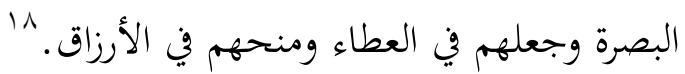
من هنا ظهر اللحن، واستبد الخاصة والعامة، مما جعل الولاة والخلفاء يفكرون في وضع الأسس التي تصون اللغة وتخفظها من عبث العابثين. وكان من أهم هذه الأسس الإشتغال بالدراسة النحوية ووضع القواعد. وإن علماء البصرة هم الذين احتضنوا الدراسة النحوية لأنها في بلدهم نشأت وفي مدينتهم تكونت وعلى يدهم أخذت تنمو شيئا فشيئا وتطور حينا بعد حين حتى صار علما على صورته النهائية. 


$$
\text { وإن ثمة أسبابا دعت إلى ظهور علم النحو في مدينة البصرة:19 }
$$

ا ـ إن العرب النازحين إليها من القبائل العريقة في اللغة العربية الفصحى، وأفم استطابوها واتخذ وهادارهم. ولكنهم في نفس الوقت فقدوا فصاحتهم نتيجة من الإختلاط بالأعاجم فيها، فقاموا بوضع علم يردون به فصاحتهم. طبعا أفم يدافعون فصاحة لغتهم نتيجة من اختلاط بالأعاجم فيها، فقاموا بوضع العلم لحرص عن فصاحتهم. r. كان في البصرة "المربد" الذي اتخده العرب سوقا. وصارت هذه السوق في الإسلام صورة معدّلة لعكاظ الجاهلية. فكانت فيه النوادى الأدبية والمجامع الثقافية. فقد كان الشعراء يؤمونه ومعطم رواتم، وكذلك النحويون يسمعون فيه ما يصحح قواعدهم ويؤيد مذاهبهم. r. إن موقع البصرة الجغرافي على طرق البادية مما يلي العراق وأدنى المدن إلى العرب إلا قحاح الذين لم تلوث لغتهم بعامية الإمصار. والأعراب تفد إليها من بوادى غربا والبحرين جنوبا. وهذه كلها مما يسر علماء البصرة حينما قاموا بوضع القواعد النحوية، وإفم وجدوا ما فيها ما لم يوجد في غيرها حتى أنه ليس مستغربا إذا كانت البصرة أول مدينة عنيت بعلم النحو، ومن هنا انطلقت حركة نحوية. وهذا العلم لم تطل مدة حضانته كغيره من العلوم المختلفة، ولكن مشى واكتمل بخطوات واسعة، لأن العرب يشعرون بالحاجة إليه. وما أن استهل العصر العباسي إلا وهوعلم يدرس في البصرة ثم الكوفة

$$
\begin{aligned}
& \text { وغيرها من المدن الإسلامية. } \\
& \text { د. أول واضع النحو العربي }
\end{aligned}
$$

فتح المسلمون البصرة سنة الخامسة العشرة للهجرة، في أيام خلافة عمر بن الخطاب رضي الله عنه. وبعد الفتوحات انتشرت اللغة العربية جنبا بجنب مع انتشار الإسلام، فذهبت أينما ذهب وانتشرت أينما انتشر. فتلك الفتوحات تؤدي إلى أن يحتلط مسلموا العرب بسكاها الأصليين، ونشأ من هذا الإختلاط بذور اللحن في ألسنة بعض متكلميها. فاحتاج العرب إلى علم حيث يحفظ سلامة لغتهم من الفساد، ويسمى فيما بعد بعلم النحو.

إن ثمة خلافا حول نشأة علم النحو، منه ما يتعلق بأول من وضعه، وهذا الخلاف كما نجده في

$$
\begin{aligned}
& \text { العصر الحاضر نجده أيضا في العصر القديم. } \\
& \text { 1. الحخلاف القديم }
\end{aligned}
$$

إن الخلاف حول أول من وضع النحو في العصر القديم نستطيع أن نجده في الكتاب أخبار النحويين

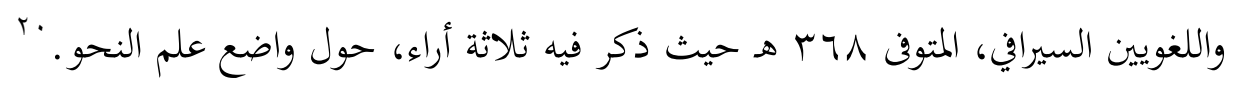


أ) الرأي الأول لعاصم الذي ذهب إلى أن واضع علم النحو هو أبو الأسود الدؤلي، وقد قال

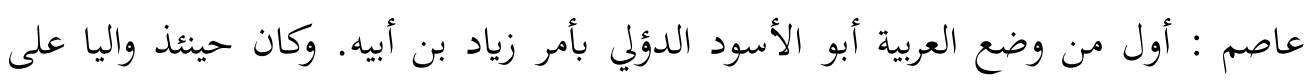

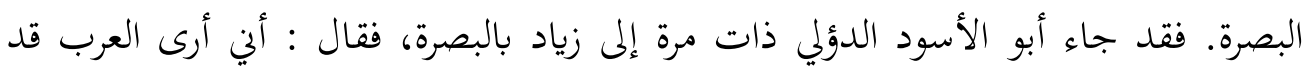

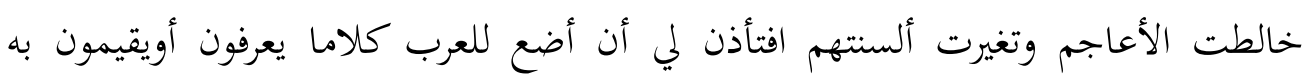

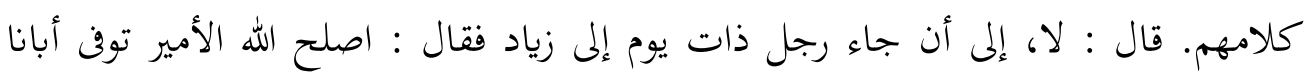

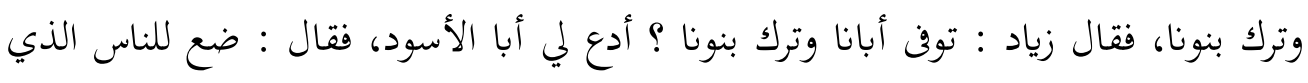
هيتك أن تضع لهم. ب) الرأي الثاني لخالد الخداء الذي ذهب إلى أن واضع علم النحو هو نصر بن عاصم. وقد قال

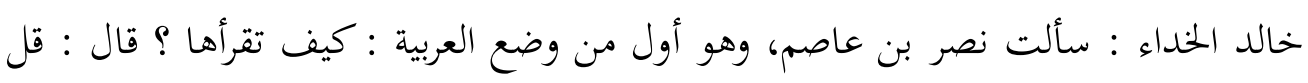

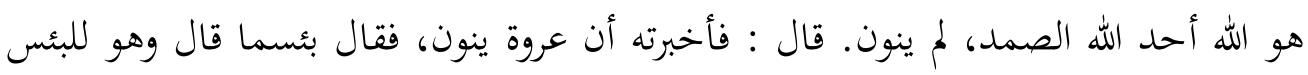
أهل. ج) الرأي الثالث لأبي النضر الذي ذهب إلى أن عبد الرحمن بن هرمز هو أول من وضع النحو

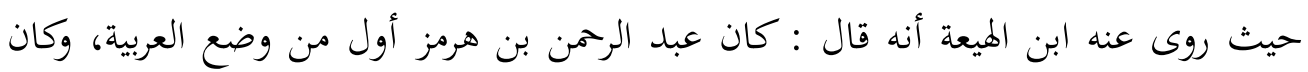

$$
\begin{aligned}
& \text { أعلم الناس بأنساب قريش واحد القراء. } \\
& \text { r. الخلاف في العصر الحديث }
\end{aligned}
$$

وأما في عصرنا الحاضر فالخلاف في هذا الأمر فليس بأقل من القديم شأنا، ولمعرفة هذا الخلاف

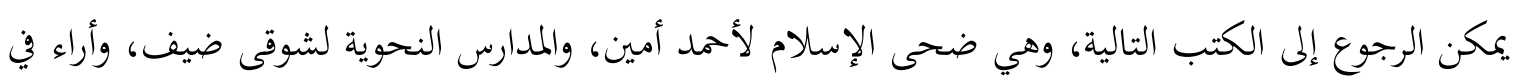
اللغة لأممد عبد الغفور عطار.

لعل أول من أثار هذه القضية في العصر الحديث إبراهيم مصطفى حين ألقى بحثه تحت عنوان (أول

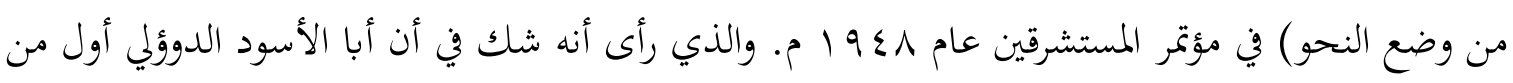

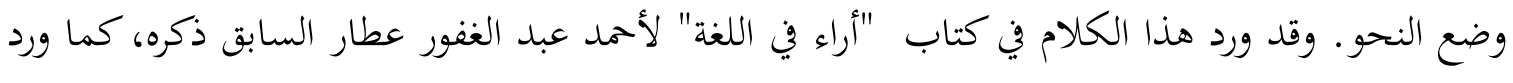

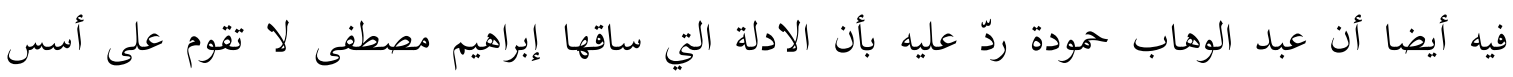
علمية.

أما أحمد أمين فقد رفض الرأي القائل أن عليا هو أول من وضع علم النحو وفقا للروايات التي تذكر

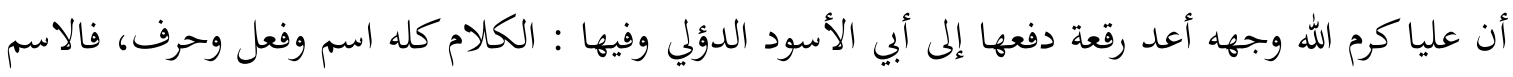

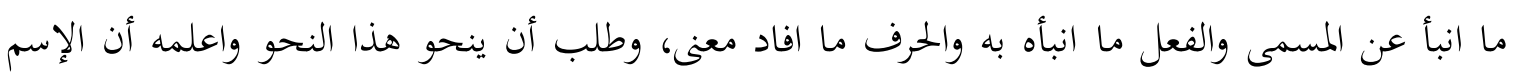

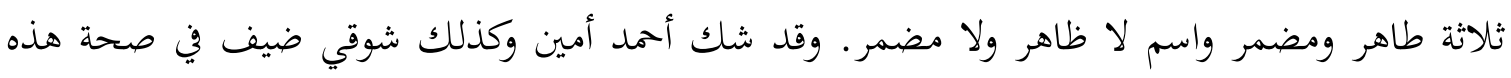


الروايات، لأن الظروف السياسية المضطربة طوال عهده بالخلافة لا تسمح له بالفكر في مثل هذه المسأله وزعما أهما من اختلاف الشيعة.

وإذا كان العالمان الفضلان أحمد أمين وشوقي ضيف قد اتفقا على رفض الرأي القائل إن عليا هو

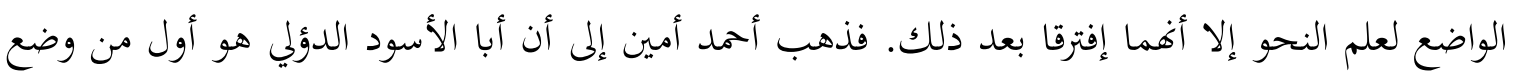

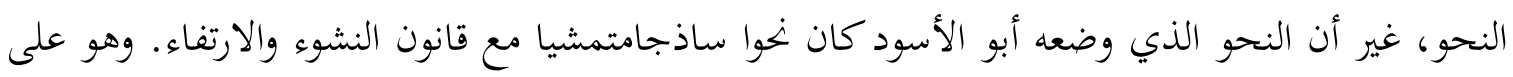

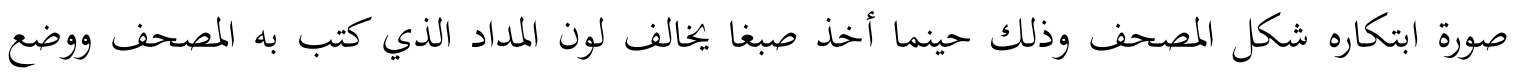

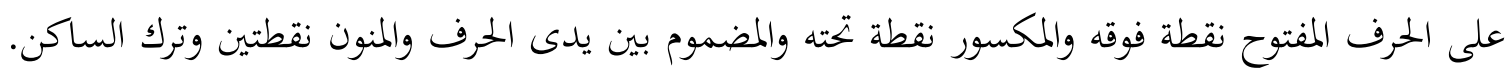

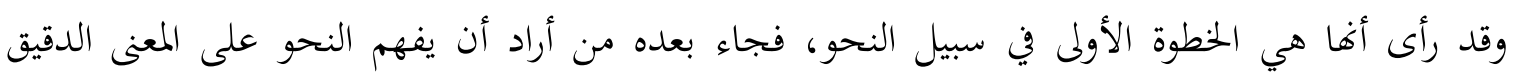
فاخترع تقسيم الكلمات إلى اسم وفعل وحرف. أما شوي ضيف فقد رأى أن أول من وضع عحرف علم النحو بالمعنى الدقيق هو عبد الله بن أبي اسحق

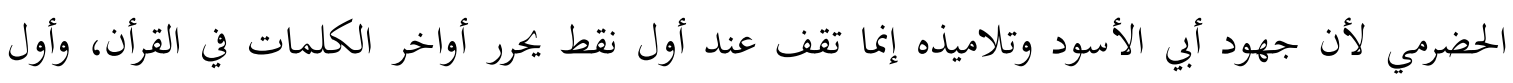

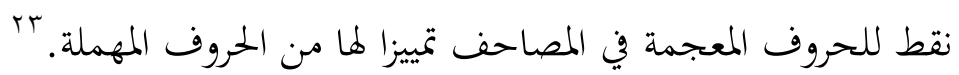

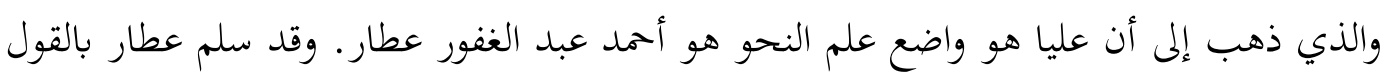

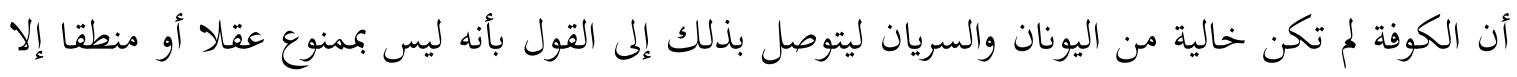

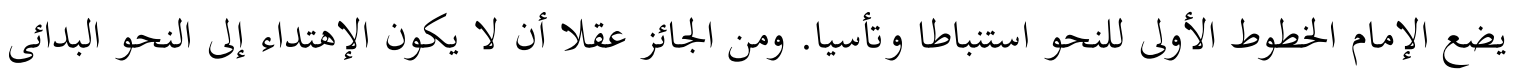

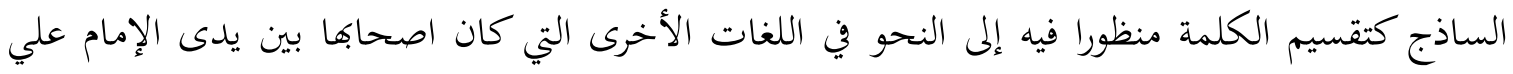

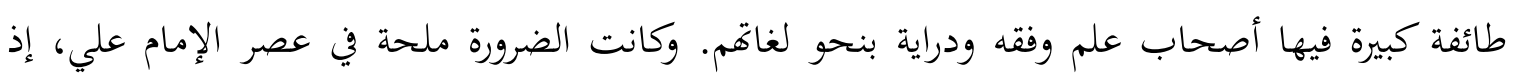

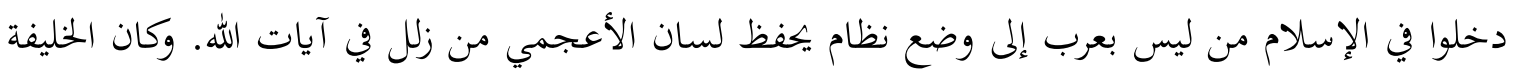

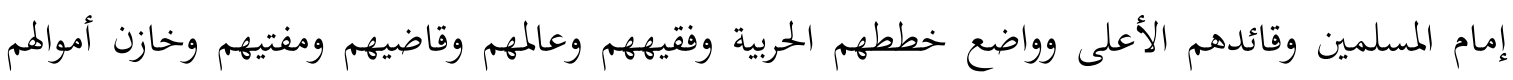

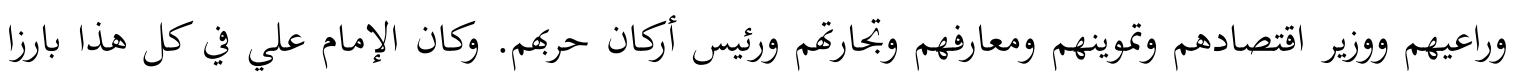

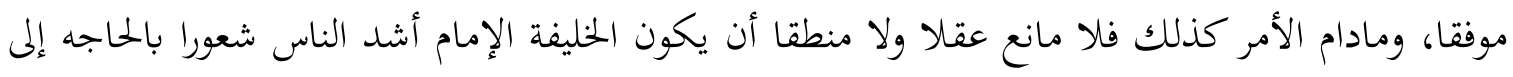

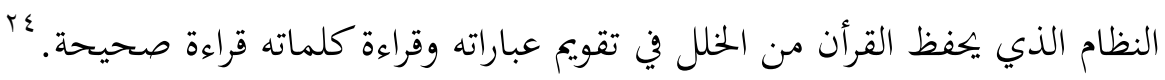

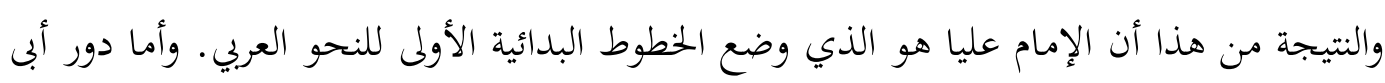

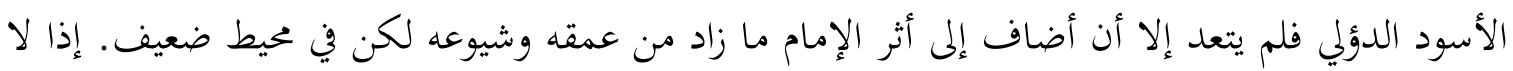

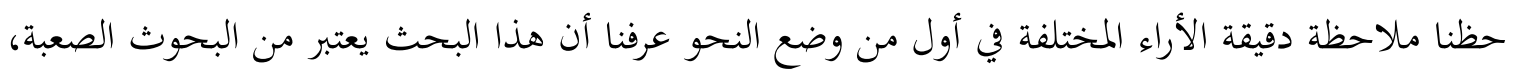

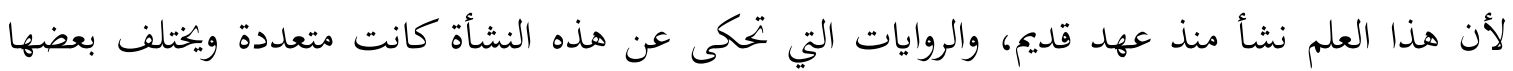


ببعض. ولتحقيق صحة الروايات فليس بسهل لعدم وجود الضوابط له. مهما كانت كذلك لو اهتممنا إلى

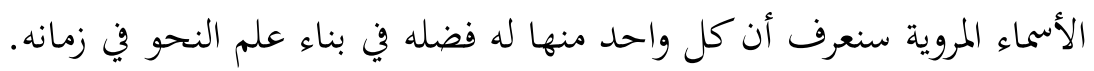

هـ. الاستنباطات

بعد أن انتهى الكاتب من البحث فيما يتعلق بنشأة النحو العربي، يرى أن يقدم تلخيصا موجزا في

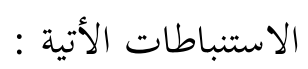

1. إن اهتمام بسلامة اللغة العربية قد ظهر منذ عصر صدر الإسلام ويكون فيما بعد سببا لنشأة علم

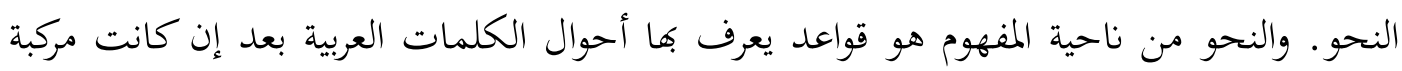

جملا، وكيف ضبط أواخرها وإعرابها ووظيفتها في الجملة.

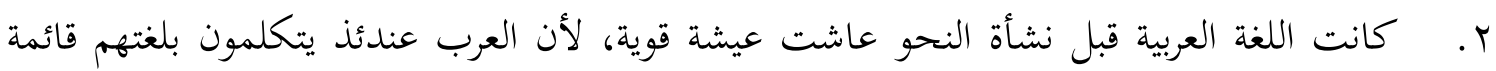

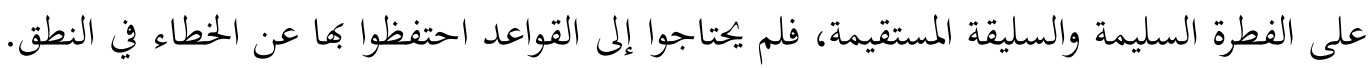

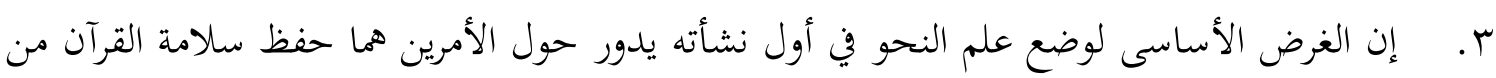

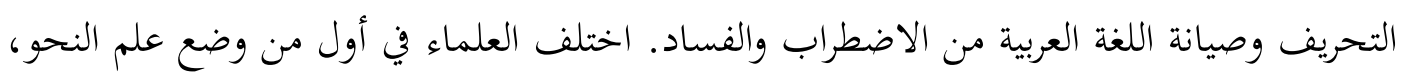

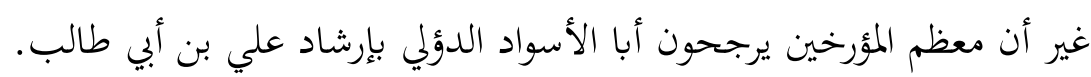

أمين، أحمد. 910 أ. فجر الإسلام. سنقافورا: سليمان مرعي. . 9 و 1 ـ ضحى الاسلام. لجنة التأليف والترجمة والنشر.

أنيس، إبراهيم. 9 I I معجم الوسيط. مصر: دار المعارف.

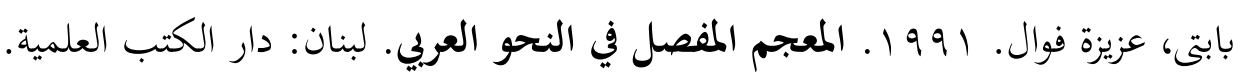
البيجورى، إبراهيم. فتح رب البرية. سمارانج: مكتبة اوساها كلواركا.

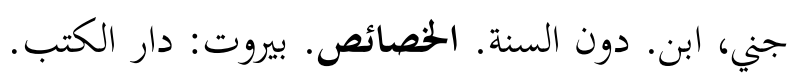

حسان، تمام. 9 أ. اللغة العربية معناها ومبناها. مصر : الميئة المصرية العامة.

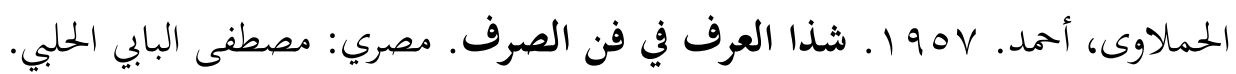
دحلان، احمد زيني. دون السنة. شرح مختصر جدا على متن الأجرومية. سورابايا: المكتبة الثقافة. رضا، علي. دون السنة. المرجع في اللغة العربية. دون المطبعة. 
الزيات، أحمد حسن. دون السنة. تاريخ الأدب العربي. دون المطبعة. السيرافي. و I I ا ـ أخبار النحويين البصريين. بيروت: المطبعة الكثوليكية. ضيف، سوقي. r ب ا9 ا ـ المدارس النحوية. القاهرة: دار المعارف. الطنطاوي، محمد. دون السنة. نشأة النحو وتاريخ أشهر النحاة. دون المطبعة. العلي، صالح أحمد. به 90 ـ ـ التنظيمات الاجتماعية في البصرة. بغداد: مطبعة المعارف. عطار، عبد الغفور أحمد. عـ 9 ا ـ أراء في اللغة. جدة: المؤسسة العربية للطباعة. الغلايني، مصطفى. ع 9 1 ـ جامع الدروس العربية. بيروت: المكتبة العصرية. مكرم، عبد العال سالم. دون السنة. القرأن وأثره في الدراسات النحوية. مصر: دار المعارف. الهاشمي، أحمد. دون السنة. القواعد الأساسية اللغة العربية. جاكارتا: ديناميكا بركة أوتاما. 